\title{
Re: "Effectiveness Analysis of Percutaneous Kyphoplasty Combined with Zoledronic Acid in Treatment of Primary Osteoporotic Vertebral Compression Fractures"
}

\section{TO THE EDITOR:}

We have read the article entitled, "Effectiveness analysis of percutaneous kyphoplasty combined with zoledronic acid in treatment of primary osteoporotic vertebral compression fractures" recently published in your valuable journal (1). It is clear that patients with lower bone mineral density are at increased risk of fracture (2). Adoption of effective fracture prevention strategies in high-risk patients especially in the first year after a fracture is prudent (3). It seems that calcium supplementation alone is not effective enough in reducing fracture risk in this group of patients, and vitamin $D$ should be added to the maintenance regimen of all patients who are at increased risk of osteoporotic fractures (4). Zoledronic acid as a bisphosphonate is a well-established treatment option in osteoporosis $(2,5)$. Perhaps it would have been better if Huang et al (1) had given the control group patients another bisphosphonate, such as alendronate, or added vitamin $D$ to their calcium treatment regimen.

Reza Aminnejad, MD

Shahid Behesti University of Medical Sciences

School of Medicine

Iran

E-mail: r.aminnejad@yahoo.com

\section{References}

1. Huang ZF, Xiao SX, Liu K, Xiong W. Effectiveness analysis of percutaneous kyphoplasty combined with zoledronic acid in treatment of primary osteoporotic vertebral compression fractures. Pain Physician 2019; 22:63-68.

2. Iqbal SM, Qamar I, Zhi C, Nida A, Aslam $\mathrm{HM}$. Role of bisphosphonate therapy in patients with osteopenia: A systemic re- view. Cureus 2019; 11:e4146.

3. Kanis J, Cooper C, Rizzoli R, et al. Identification and management of patients at increased risk of osteoporotic fracture: Outcomes of an ESCEO expert consensus meeting. Osteoporos Int 2017; 5 28:2023-2034.

4. Weaver CM, Alexander DD, Boushey CJ, et al. Calcium plus vitamin D supplementation and risk of fractures: An updated meta-analysis from the National Osteoporosis Foundation. Osteoporos Int 2016; 27:367-376.

Dhillon S. Zoledronic acid (Reclast((R)), Aclasta((R))): A review in osteoporosis. Drugs 2016; 76:1683-1697. 